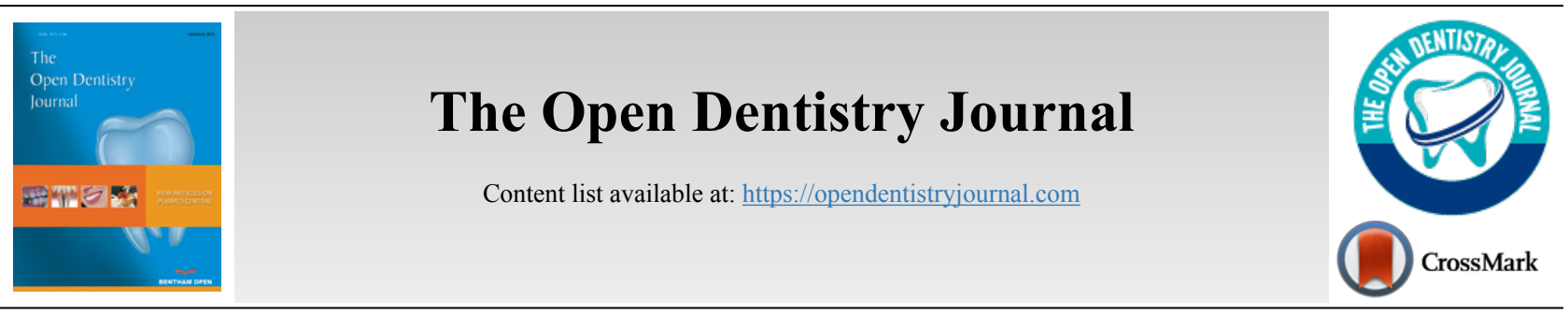

RESEARCH ARTICLE

\title{
Patients' Preferences for Dentist's Nationality and Gender among Residents of Jeddah, Saudi Arabia
}

Shrooq Alzahrani ${ }^{1, *}$, Khalid Aboalshamat ${ }^{2}$, Samaher Bedaiwi ${ }^{1}$, Sarah Alnefaie ${ }^{1}$, Taghreed Almutairi ${ }^{1}$, Saja Asiri ${ }^{1}$ and Ibtihal Alnuwaymi ${ }^{1}$

${ }^{1}$ Department of Dentistry, Alfarabi college, Jeddah, Saudi Arabia

${ }^{2}$ Preventative Dentistry Department,Dental Public Health Division, College of Dentistry, Umm Al-Qura University, Makkah, Saudi Arabia

\begin{abstract}
:
Introduction:

Several studies have shown that a dentist's gender and nationality are important factors for patients when they choose their dentist. This topic is important in countries like Saudi Arabia, which is considered to be conservative and has many cultural boundaries that separate men from women in daily activities.

Aim:

This study aimed to investigate patient preference for a dentist's gender among a sample population in Jeddah, Saudi Arabia.

Methods:

This cross-sectional study recruited 1,000 participants who completed a self-administered questionnaire. Data were analyzed using SPSS v.21.

Results:

A total of $46.2 \%$ of the participants had no particular gender preference for dentists in general, while $28.6 \%$ prefered male dentists and $25.2 \%$ prefered female dentists. Male and female participants had statistically significant differences in the selection of a dentist's gender in general, with all participants tending to choose a dentist of the same gender as themselves. Previous personal experience and recommendations from friends were among the most influential factors in choosing dentists of a specific gender. In terms of preferences for dentists of a particular nationality, $45.6 \%$ had no preferences, while $28.4 \%$ preferred Saudi dentists.

Conclusion:

Although half of the Jeddah residents participating in our study had no preference for dentists of a particular gender or nationality, the other half had specific preferences.
\end{abstract}

Keywords: Dentistry, Gender preference, Nationality preference, Patient preference, Cross-sectional study, Patient.

\begin{tabular}{|l|l|l|r}
\hline Article History & Received: January 14, 2020 & Revised: March 09, 2020 & Accepted: March 13, 2020
\end{tabular}

\section{INTRODUCTION}

Several studies have been conducted to assess patients' preferences for health care providers [1], including some that have investigated patients' preferences for dentists [2 - 5]. These studies showed that dentist demographic variables such as gender and nationality are significantly important when patients choose their dentists. However, there are few articles

\footnotetext{
* Address correspondence to this author at the Department of Dentistry, Alfarabi college, Jeddah, Saudi Arabia; Tel: (+966) 543201763, Fax: 21488; E-mail: Shrooq11001@gmail.com
}

investigating the factors i.e dentist's gender and nationality from the perspective of adult patients, as opposed to children toward dentists $[6,7]$ or the attitudes of children and adults toward other health practitioners [8 - 10].

In fact, the study of such a topic may not be important in some countries, but it is crucial in others. For example, Saudi Arabia is a country where there are many cultural boundaries and organizational rules that tend to separate men and women in daily activities $[11,12]$. In addition, many Saudi women cover their face with a veil called a hijab, which may affect 
their attitudes and choices in selecting a dentist of one gender or the other. Also, Saudi Arabia has an unequal distribution of male and female dentists [13], which makes it more challenging to access dentists according to a patient's preference, and it could be a critical factor in life-threatening situations if a patient refuses to be examined by a health care practitioner because of his or her gender. In fact, exploring patient preferences is important to optimize patient satisfaction and comfort and to enhance the convenient delivery of highquality health care to patients [14].

Public preference for a dentist's gender has been found to vary between different countries. A study in England found that participants preferred female dentists [5], while two other studies, in Sudan [15] and Turkey, found that patients preferred dentists of their gender, especially females [4]. On the other hand, a study conducted in India found that half of the participants had no gender preferences when choosing a dentist [16]. Only one study that has been previously conducted in Saudi Arabia, in Riyadh, showed that $40 \%$ of respondents had no gender preference, while $33 \%$ preferred a male dentist, and $26 \%$ preferred a female dentist [14]. The preferences indicated differing attitudes among male and female participants, with males tending to be more gender-oriented in selecting male dentists, in contrast to female participants, who did not show significant differences in the selection of a male orfemale dentist or having no gender preferences. Furthermore, the Riyadh study indicated that gender preferences sometimes are dependent on the dental procedure, with participants preferring female dentists for treating their children, while male dentists were preferred for surgical dental treatments.

Studies have also investigated other factors that can influence the choice of a dentist, including the dentist's nationality [14], educational level [4], and the type of treatment $[4,14]$. One study conducted in Saudi Arabia revealed the percentage of patients showing a preference for Saudi dentists, non-Saudi dentists, or no preferences being 19\%, 14\%, and $67 \%$, respectively [14]. Another study conducted in England found that participants from different ethnic backgrounds exhibited distinct preferences with regard to their dentist's age [5]. Other studies have highlighted non-demographic variables influencing the choice of a dentist, such as competence, word of mouth popularity, and service quality [17].

Nevertheless, the current studies conducted in Saudi Arabia are not enough to give a more generalizable picture of patient preferences. Therefore, this study aimed to investigate patient preferences based on a dentist's gender and nationality in Jeddah, one of the major cities in Saudi Arabia.

\section{MATERIALS AND METHODS}

\subsection{Study Design and Sample}

This study is a descriptive cross-sectional study of Jeddah residents. Exclusion criteria included participants younger than 18 years old and those who did not live in Jeddah. An estimated prevalence of $50 \%$, precision use of $5 \%$, and a confidence level of $95 \%$ yielded 385 participants as the required minimum sample size for this study.

A convenient sample was used to recruit participants from four large shopping malls (Al Salaam Mall, Red Sea Mall, AlMurjan Mall, and Mall of Arabia) that represent the north, east, center, and south areas of Jeddah, aiming for the most representative sample possible.

\subsection{Data Collection}

The data was collected in June and July of 2018 and it took approximately five minutes for each participant to complete. The questionnaire was composed of 24 questions divided into four sections. The first section included demographic questions encompassing age, gender, education level, marital status, nationality, and monthly household income. The second section focused on preferences for a dentist's gender in addition to other circumstances that may affect preferences, such as whether a dental visit was for surgical or cosmetic reasons or if the visit to the dentist was for the participant's child. This section also asked about the influence of other factors such as culture, religion, parents' or spouse's opinion, previous experience, friends' experiences, and shyness. The third section focused on participants' preferences for a dentist's nationality and sought participants' opinion on whether a dentist's nationality is related to his or her performance. Also included in this section was a question asking if the participants preferred to be treated by a dentist from the same tribe or family. The fourth section focused on other factors that might affect a patient's choice, including the dentist's age, reputation, or credentials; if the clinic was private or government-run; and recommendations from friends. Finally, the questionnaire included two questions to be answered by only female participants who wore a face veil: 1) if the face veil affected their choice of dentist's gender and 2) whether they would expose their entire face to a male dentist or only the mouth area. The questionnaire is given as appendix A.

\subsection{Data Analysis}

Data analyses were conducted using SPSS v.21 software (IBM, Armonk, NY, USA), with frequency tables and descriptive statics and where chi-square tests used $p=0.05$ as the statistically significant level.

\subsection{Ethical Considerations}

Approval was taken from the mall administrators, and all the participants signed study consent forms before participation. All data were treated anonymously, and any identifiable data were excluded . Ethical approval for the study was received from Alfarabi Dental College in Jeddah, Saudi Arabia.

\section{RESULTS}

Data were collected from 1,000 participants with a mean age of 31.20 years and a standard deviation of 10.70. Detailed demographic data for participants are given in Table 1. Patient preferences for dentist's gender in different situations are catergorized in Table 2.

Using chi-square analysis, the differences in preferences shown by men and women participants in selecting a specific gender of dentist are statistically significant $(p<0.001)$. For male participants, $31 \%$ preferred male dentists, $18.6 \%$ 
preferred female dentists, and 50.2\% had no preferences. For female participants, $26 \%$ preferred male dentists, $31.8 \%$ preferred female dentists, and $42.2 \%$ had no gender preferences. Male and female participants' choices of gender of dentist for surgical treatments were not statistically different.

Table 1. Demographic data on study participants.

\begin{tabular}{|c|c|c|}
\hline \multicolumn{2}{|r|}{-} & Frequancy $(\%)$ \\
\hline \multirow[t]{2}{*}{ Sex } & Male & $500(50.0 \%)$ \\
\hline & Female & $500(50.0 \%)$ \\
\hline \multirow[t]{3}{*}{ Education } & Less than high school & $84(8.4 \%)$ \\
\hline & High school & $362(36.2 \%)$ \\
\hline & Postgraduate degree & $554(55.4 \%)$ \\
\hline \multirow[t]{3}{*}{ Occupation } & Student & $228(22.8 \%)$ \\
\hline & Employee & $513(51.3 \%)$ \\
\hline & Unemployed or housewife & $259(25.9 \%)$ \\
\hline \multirow[t]{2}{*}{ Marital status } & Not married & $479(47.9 \%)$ \\
\hline & Married & $521(52.1 \%)$ \\
\hline \multirow[t]{3}{*}{ Income } & Less than 5,000 & $288(28.8 \%)$ \\
\hline & $5,000-10,000$ & $413(41.3 \%)$ \\
\hline & More than 10,000 & $299(29.9 \%)$ \\
\hline \multirow[t]{2}{*}{ Nationality } & Saudi & $728(72.8 \%)$ \\
\hline & Non-Saudi & $272(27.2 \%)$ \\
\hline
\end{tabular}

Table 2. Participants' gender preferences for dentists in various circumstances.

\begin{tabular}{|c|c|c|c|}
\hline & Male & Female & No Preference \\
\hline $\begin{array}{c}\text { Generally, I preferred to } \\
\text { be treated by a dentist } \\
\text { who is: }\end{array}$ & $\begin{array}{c}286 \\
(28.6 \%)\end{array}$ & $252(25.2 \%)$ & $462(46.2 \%)$ \\
\hline $\begin{array}{c}\text { For dental surgery, I } \\
\text { prefer a dentist who is: }\end{array}$ & $\begin{array}{c}426 \\
(42.6 \%)\end{array}$ & $211(21.1 \%)$ & $363(36.3 \%)$ \\
\hline $\begin{array}{c}\text { For cosmetic dentistry, I } \\
\text { prefer a dentist who is: }\end{array}$ & $\begin{array}{c}273 \\
(27.3 \%)\end{array}$ & $327(32.7 \%)$ & $400(40.0 \%)$ \\
\hline $\begin{array}{c}\text { I prefer for my child (my } \\
\text { future child) to be treated } \\
\text { by a dentist who is: }\end{array}$ & $\begin{array}{c}257 \\
(25.7 \%)\end{array}$ & $279(27.9 \%)$ & $464(46.4 \%)$ \\
\hline
\end{tabular}

Table 3. Factors potentially influencing patient preference of dentist gender.

\begin{tabular}{|c|c|}
\hline Factor & Frequency (\%) \\
\hline Previous experience & $387(38.7 \%)$ \\
\hline Friends' experience & $296(29.6 \%)$ \\
\hline Nothing affects preference for dentist's gender & $244(24.4 \%)$ \\
\hline Preferred gender "is more confident" & $240(24.0 \%)$ \\
\hline Religious beliefs & $186(18.6 \%)$ \\
\hline Cultural beliefs & $141(14.1 \%)$ \\
\hline Shyness & $140(14.0 \%)$ \\
\hline Opinion of spouse/parents & $123(12.3 \%)$ \\
\hline Societal norms & $82(8.2 \%)$ \\
\hline
\end{tabular}

Among female participants $(n=500), 14.6 \%$ preferred not to go to a male dentist because they cover their faces. Of the female participants, $17.2 \%$ said they would expose only their mouth region when receiving treatment from a male dentist.
Table 3 shows the various other factors chosen by participants as potentially influential in their choice of one gender over the other when selecting a dentist.

The analysis shows that $33.7 \%$ of the participants in this study consider nationality to be an influential factor when choosing a dentist. Furthermore, $32.6 \%$ of respondents believe that a dentist's nationality determines the quality of treatment. The chi-square test revealed a statistically significant difference $(p<0.001)$ in the responses of males and females, and more male participants (38\%) had this belief than did female $(27.2 \%)$ respondents. Participants' preferences with regard to dentist's nationality are shown in Table 4 .

Table 4. Percentage of participants preferring a dentist of a specific nationality.

\begin{tabular}{|c|c|}
\hline Factor & Frequency (\%) \\
\hline Nationality does not matter & $456(45.6 \%)$ \\
\hline Saudi & $284(28.4 \%)$ \\
\hline Syrian & $181(18.1 \%)$ \\
\hline Egyptian & $94(9.4 \%)$ \\
\hline Filipino & $56(5.6 \%)$ \\
\hline Indian & $48(4.8 \%)$ \\
\hline Other nationality & $48(4.8 \%)$ \\
\hline Lebanese & $36(3.6 \%)$ \\
\hline
\end{tabular}

Table 5. Other factors affecting patient preferences for a dentist.

\begin{tabular}{|c|c|c|}
\hline Factors & Options & Frequency (\%) \\
\hline Dentist age preference & Older dentist & $318(31.8 \%)$ \\
\cline { 2 - 3 } & Younger dentist & $68(6.8 \%)$ \\
\cline { 2 - 3 } & No preference & $614(61.4 \%)$ \\
\hline Dentist reputation & Well-known & $605(60.5 \%)$ \\
\cline { 2 - 3 } & Not particularly well-known & $40(4.0 \%)$ \\
\cline { 2 - 3 } & No preference & $355(35.5 \%)$ \\
\hline Dentist certificate & $\begin{array}{c}\text { Certificate from outside } \\
\text { Saudi Arabia }\end{array}$ & $240(24.0 \%)$ \\
\cline { 2 - 3 } & Certificate from Saudi & $71(7.1 \%)$ \\
& Arabia & \\
\cline { 2 - 3 } & No preference & $689(68.9 \%)$ \\
\hline Dentist clinic type & Government clinic & $145(14.5 \%)$ \\
\cline { 2 - 3 } & Private clinic & $383(38.3 \%)$ \\
\cline { 2 - 3 } & No preference & $472(47.2 \%)$ \\
\hline \multirow{2}{*}{$\begin{array}{c}\text { Dentist } \\
\text { recommendations }\end{array}$} & With recommendation & $554(55.4 \%)$ \\
\cline { 2 - 3 } & No preference & $446(44.6 \%)$ \\
\hline
\end{tabular}

With regard to whether or not patients prefer to be treated by a dentist from their tribes/ family, the results show that $66.6 \%$ of the respondents do not consider a dentist's family or tribe to be important in their choice of dentist, while $14.1 \%$ preferred being treated by a dentist from their tribe/family. However, $19.3 \%$ preferred not to be treated by a dentist from their tribe. It should be noted that being treated by a dentist from the same nationality is different from being treated by a dentist from the same tribe or family. A chi-square analysis indicated that the differences in answers by male and female participants were statistically significant $(p<0.001)$. Female 
participants $(23.8 \%)$ were less likely to prefer to be treated by a dentist from their tribe than were males (14.8\%).

Participants were also asked about other factors that might be important when choosing a dentist, and some of those factors are shown in Table $\mathbf{5}$ along with the number of participants considering them as important in selecting a dentist.

\section{DISCUSSION}

Our results showed that almost half of the participants have no specific gender preferences when choosing a dentist for treatment. Among the remaining participants, male dentists were more preferred generally and when selecting a dentist for surgical procedures, but female dentists were more preferred for cosmetic and pediatric dental treatments. Among those who showed a preference for a specific gender, female participants tended to choose female dentists, and male participants tended to choose male dentists.

In addition, around half of the participants had no preferences with regard to dentist's nationality. Among the participants who did have a preference, Saudi dentists were the most preferred, followed by Syrian and Egyptian dentists.

Our results with regard to gender preference are similar to previous studies conducted in Sudan [15] and India [4] in that most of our participants either had no gender preference or preferred to be treated by the same gender. Interestingly, our results and those found in the other Saudi study conducted in Riyadh [14] had many similar results. Both the studies found that the majority of participants had no preference for gender, and showed similar proportions of respondents preferring male dentists (second most chosen response) or female dentists. Furthermore, both studies indicated that participants prefer male dentists for surgical treatment and female dentists to treat their children. Previous studies have indicated that male dentists are viewed as more skilled, experienced, confident, competent, career-oriented, and professional [15, 16, 18], although female dentists were seen as having more empathy with their patients [16]. The similarities in the results of our study and the previous Saudi study can give external validity to the result across Saudi Arabia. One further explanation for preferring male dentists can be due to a higher ratio of male dentists compared to female dentists in Saudi Arabia [13]. However, such an explanation need further study for confirmation.

It should be mentioned that our results regarding gender preference were different from from the results of similar studies conducted in Western countries such as England [5], where it was found that female dentists were more preferred. This might be explained by cultural differences between the Middle East/Asian countries with other Western countries.

Despite our expectations, a preference for one gender over the other when selecting a dentist was not widely influenced by religious, cultural, societal, or familial influences, in contrast to other factors, such as a dentist's previous experience, recommendations from friends, or a dentist's level of confidence, which were found to be more important in influencing preferences for one gender over the other.
Our study also included female participants who wear face veils and prefer not to go to a male dentist to avoid having to expose their faces. Some of these women answered that they would go to a male dentist if necessary, but they would only expose their mouth area. While this cultural factor might not be a prominent issue for the majority, it is an important issue with a considerable percentage of female participants. Thus, it is recommended to increase awareness among female patients that exposing only the mouth area may hinder proper dental care and increase the risk of infection by violating the standards for infection control. At the same time, however, it is also recommended that attention should be paid to increasing the number of qualified female dentists to meet public needs and to respect these religious and cultural beliefs.

In terms of nationality, our results were again similar to the Riyadh study in that around half of the participants had no preferences for dentists of a particular nationality, while the rest preferred Saudi dentists over other nationalities. In fact, this is in agreement with the study from England [5] where English participants preferred to use English dentists. This may indicate a tendency to prefer dentists with nationalities similar to the patient, but it is important to bear in mind that nationality is not the most crucial factor; other studies have indicated that patients readily accept a practitioner from a different background if the dentist is believed to be qualified [19]. However, this is an important factor in Saudi Arabia given that, according to the Saudi Commission of Health Specialties, there are only 3,720 Saudi dentists [13] currently in practice out of the original total of 16,887 registered dentists in Saudi Arabia. Thus, it is suggested to increase the number of certified Saudi dentists to meet public demand and establish optimal patientdentist relationships.

Furthermore, a dentist's tribe/family was found to be another dimension that can be relatively important in countries with strong social bonds, such as Saudi Arabia. While twothirds of our respondents do not consider a dentist's tribe to be an important factor, some participants did state a preference for being treated by a dentist from their tribe/family, while another proportion, mostly female, expressed a preference not to be treated by a dentist from their tribe/family. This result might seem somewhat surprising, but may be explained by the fact that women do not want to expose their medical condition to a relative who could potentially leak information among the same family or tribe. Nevertheless, this issue needs further qualitative investigation to pinpoint the reason for this result.

Our results also highlighted other factors that add to the complexity of choosing a dentist in Saudi Arabia. While the majority of respondents had no preferences for dentist's age, qualifications, or type of clinic, they were concerned to some extent about the dentist's reputation, and they valued recommendations from friends. This may be due to a desire to seek validation of the quality of a dentist to increase trust in receiving quality dental care.

The strengths of this study include the large sample size as well as the inclusion of Hijabi women and tribal factors that have not been examined in similar studies. However, this study has some limitations, including the use of a self-reported questionnaire and a convenient sample, which decreased the 
level of external validity.

\section{CONCLUSION}

This study revealed that nearly half of the participants had no preferences for dentist's gender or nationality. However, among the ones who do have a specific preference, participants preferred male dentists over female dentists, especially for surgical procedures. Also, among those who had a preference for a specific nationality, Saudi dentists were preferred over other nationalities. Our study supports the prior local study, adding external validity to the findings.

\section{ETHICS APPROVAL AND CONSENT TO PARTICIPATE}

The project received ethical approval from Alfarabi Dental College in Jeddah, Saudi Arabia, with approval no10/09/2018.

\section{HUMAN AND ANIMAL RIGHTS}

Not applicable.

\section{CONSENT FOR PUBLICATION}

All participants signed the study informed consent before answering the study questionnaire.

\section{AVAILABILITY OF DATA AND MATERIALS}

All data that support the results of this study are with the corresponding author, [S.A.] and can be made available upon reasonable request.

\section{FUNDING}

None.

\section{CONFLICT OF INTEREST}

The authors declare no conflict of interest, financial or otherwise.

\section{ACKNOWLEDGEMENTS}

The authors would like to thank Rehhaf A. Sindi, Reem H. Alshekhi, Johara A. Sindi, Bushra M. Almotairi, Meaad M. Aldairi, Miad S. Almajnuni, Shahad M. Baheydrah, and Bashair A. Alsaud for collecting the data. We also want to acknowledge Dr. Mysoon Hassan and Dr. Abdelhamid Gaber for their supervision of this study.

\section{APPENDIX A}

Please answer the following questions. All of your personal information will be treated confidentially, and no one will look at the answers you provided.

\section{Section One: Demographic data:}

\begin{tabular}{|c|c|}
\hline Age please write a number & Gender \\
\hline . & $\begin{array}{c}\text { o Male } \\
\text { o Female }\end{array}$ \\
\hline Level of education & Are you? \\
\hline
\end{tabular}

\begin{tabular}{|c|c|}
\hline $\begin{array}{c}\text { o High school diploma. } \\
\text { o Less than high school diploma. } \\
\text { o Bachelor's degree or higher. }\end{array}$ & $\begin{array}{c}\text { o Student } \\
\text { o Employee } \\
\text { o Not employed / housewife. }\end{array}$ \\
\hline Marital status & Nationality \\
\hline $\begin{array}{c}\text { o Single } \\
\text { o Married } \\
\text { o Divorced } \\
\text { o Widower }\end{array}$ & o Saudi \\
o Non Saudi
\end{tabular}

Section two: Questions regarding to the Gender of the Preferred Dentist. Please choose the appropriate answer form the following phrases:

\begin{tabular}{|c|c|c|c|}
\hline - & $\begin{array}{c}\text { Male } \\
\text { dentist }\end{array}$ & $\begin{array}{c}\text { Female } \\
\text { dentist }\end{array}$ & $\begin{array}{c}\text { Doesn't } \\
\text { matter }\end{array}$ \\
\hline $\begin{array}{c}\text { 1- When you go to the dentist to get a } \\
\text { dental treatment, would you prefer the } \\
\text { dentist to be }\end{array}$ & - & - & - \\
\hline $\begin{array}{c}\text { 2- If your condition requires dental } \\
\text { surgical treatment (Extraction/implant } \\
\text { surgery / maxillofacial surgery), would } \\
\text { you prefer to receive dental treatment } \\
\text { from }\end{array}$ & - & - & - \\
\hline $\begin{array}{c}\text { 3- In case you need a cosmetic dental } \\
\text { treatment for your teeth as (whitening / } \\
\text { veneers "Hollywood smile"), would you } \\
\text { prefer to receive treatment from }\end{array}$ & - & - & - \\
\hline $\begin{array}{c}\text { 4- Would you prefer to treat your child's } \\
\text { teeth (or your future child) with }\end{array}$ & - & - & - \\
\hline
\end{tabular}

5. In your opinion, what are the factors that affect your choice for the dentist's gender:(You can choose more than one answer)

- Cultures and traditions

- Religious beliefs

- $\quad$ society Impact

- The influence of the husband / wife or the guardian

- Previous experiences

- Experiences of relatives and friends

- The type of gender I prefer can handle difficult cases more steadily and effectively

- Shyness

- all of these factors do not affect my decision

Section Three: Questions regarding the Nationality of the Preferred Dentist:

[1] Is the nationality of the dentist, one of the factors that affect your choice of treatment?

$$
\begin{array}{ll}
\circ & \text { Yes } \\
\circ & \text { No }
\end{array}
$$

[2] In your opinion, is there a relationship between the quality and nationality of the dentist's work?

$$
\begin{array}{cc}
\circ & \text { Yes } \\
\circ & \text { No }
\end{array}
$$

[3] What is the your preferable dentist nationality?

$$
\begin{array}{cl}
\circ & \text { Saudi } \\
\circ & \text { Syrian } \\
\circ & \text { Philippine } \\
\circ & \text { Egyptian } \\
\circ & \text { Lebanese }
\end{array}
$$




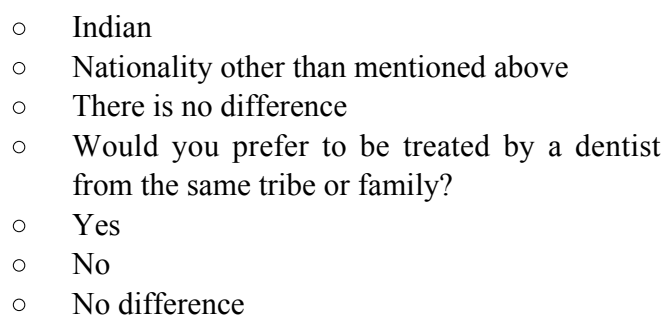

\section{Section Four: Questions related to other important factors in choosing the preferred dentist:}

What are the other factors that you think are important in choosing a dentist

\begin{tabular}{|c|c|c|c|}
\hline \multicolumn{2}{|c|}{ I prefer ... } & The factor \\
\hline $\begin{array}{c}\text { No } \\
\text { difference }\end{array}$ & Old & Young & dentist's age \\
\hline $\begin{array}{c}\text { No } \\
\text { difference }\end{array}$ & Not famous & Famous & dentist's reputation \\
\hline $\begin{array}{c}\text { No } \\
\text { difference } \\
\text { from inside } \\
\text { Saudi } \\
\text { Arabia }\end{array}$ & $\begin{array}{c}\text { certificate } \\
\text { outside Saudi } \\
\text { Arabia }\end{array}$ & dentist's certificate \\
\hline $\begin{array}{c}\text { No } \\
\text { difference }\end{array}$ & $\begin{array}{c}\text { Private } \\
\text { clinic }\end{array}$ & $\begin{array}{c}\text { Governmental } \\
\text { clinic }\end{array}$ & Clinic type \\
\hline & $\begin{array}{c}\text { I usually look for a } \\
\text { doctor who treats } \\
\text { one of my } \\
\text { acquaintances }\end{array}$ & $\begin{array}{c}\text { Recommendation } \\
\text { from friends and } \\
\text { relatives }\end{array}$ \\
\hline
\end{tabular}

If you are a female, please answer these questions:

[1] If you usually cover your face, does your face coverage prevent you from going to a male dentist?

$$
\begin{array}{ll}
\circ & \text { Yes } \\
\circ & \text { No } \\
\circ & \text { Currently, I do not cover my face }
\end{array}
$$

[2] If you usually cover your face, what do you do during the treatment?

- I expose my entire face

- I ask to reveal the mouth area only

- Currently, I do not cover my face

Thanks for your cooperation.

\section{REFERENCES}

[1] Mercado F, Mercado M, Myers N, Hewit M, Haller NA. Patient preferences in choosing a primary care physician. J Prim Care Community Health 2012; 3(2): 125-31.

[http://dx.doi.org/10.1177/2150131911421802] [PMID: 23803456]

[2] Bender DJ. Patient preference for a racially or gender-concordant student dentist. J Dent Educ 2007; 71(6): 726-45.

[PMID: 17554091]

[3] Furnham A, Swami V. Patient preferences for dentists. Psychol Health Med 2009; 14(2): 143-9.

[http://dx.doi.org/10.1080/13548500802282690] [PMID: 19235073]

[4] Gürler G, Delilbaşı Ç, Kaçar İ. Patients' perceptions and preferences of oral and maxillofacial surgeons in a university dental hospital Journal of Istanbul University Faculty of Dentistry 2018.

[5] Swami V, McClelland A, Bedi R, Furnham A. The influence of practitioner nationality, experience, and sex in shaping patient preferences for dentists. Int Dent J 2011; 61(4): 193-8. [http://dx.doi.org/10.1111/j.1875-595X.2011.00056.x] [PMID: 21851350]

[6] Patır Münevveroğlu A, Ballı Akgöl B, Erol T. Assessment of the feelings and attitudes of children towards their dentist and their association with oral health. ISRN dentistry 2014; 2014 [http://dx.doi.org/10.1155/2014/867234]

[7] Asokan A, Kambalimath HV, Patil RU, Maran S, Bharath KP. A survey of the dentist attire and gender preferences in dentally anxious children. J Indian Soc Pedod Prev Dent 2016; 34(1): 30-5.

[http://dx.doi.org/10.4103/0970-4388.175507] [PMID: 26838145]

[8] Schmid Mast M, Hall JA, Roter DL. Disentangling physician sex and physician communication style: their effects on patient satisfaction in a virtual medical visit. Patient Educ Couns 2007; 68(1): 16-22. [http://dx.doi.org/10.1016/j.pec.2007.03.020] [PMID: 17482418]

[9] Aruguete MS, Roberts CA. Participants' ratings of male physicians who vary in race and communication style. Psychol Rep 2002; 91(3 Pt 1): 793-806.

[http://dx.doi.org/10.2466/PR0.91.7.793-806] [PMID: 12530726]

[10] Laveist TA, Nuru-Jeter A. Is doctor-patient race concordance associated with greater satisfaction with care? J Health Soc Behav 2002; 43(3): 296-306.

[http://dx.doi.org/10.2307/3090205] [PMID: 12467254]

[11] Baki R. Gender-Segregated Education in Saudi Arabia: Its Impact on Social Norms and the Saudi Labor Market education policy analysis archives 2004; 12(28): 28.

[12] van Geel A. Separate or together? Women-only public spaces and participation of Saudi women in the public domain in Saudi Arabia. Contemp Islam 2016; 10(3): 357-78.

[http://dx.doi.org/10.1007/s11562-015-0350-2]

[13] AlBaker AA, Al-Ruthia YSH, AlShehri M, Alshuwairikh S. The characteristics and distribution of dentist workforce in Saudi Arabia: A descriptive cross-sectional study. Saudi Pharm J 2017; 25(8): 1208-16. [http://dx.doi.org/10.1016/j.jsps.2017.09.005] [PMID: 29204070]

[14] Huraib SB, Nahas NA, Al-Balbeesi HO, Abu-Aljadayl FM, Vellappally S, Sukumaran A. Patient preferences in selecting a dentist: survey results from the urban population of Riyadh, Saudi Arabia. J Contemp Dent Pract 2015; 16(3): 201-4.

[http://dx.doi.org/10.5005/jp-journals-10024-1661] [PMID: 26057918]

[15] Ibrahim HM, Awooda EM. Comparison of patients perception of dental care offered by male or female dentist: Cross-sectional hospital based study. Eur J Gen Dent 2015; 4(3): 117.

[http://dx.doi.org/10.4103/2278-9626.163329]

[16] Puranik MP, Kumar A. Gender Stereotypes in Dental Care: A Crosssectional Study. J Pharm Biomed Sci 2015; 5(12)

[17] Ungureanu M-I, Mocean F. What do patients take into account when they choose their dentist? Implications for quality improvement. Patient Prefer Adherence 2015; 9: 1715-20.

[http://dx.doi.org/10.2147/PPA.S94310] [PMID: 26664071]

[18] Smith MK, Dundes L. The implications of gender stereotypes for the dentist-patient relationship. J Dent Educ 2008; 72(5): 562-70. [PMID: 18451079]

[19] Gerbert B, Berg-Smith S, Mancuso M, et al. Video study of physician selection: preferences in the face of diversity. J Fam Pract 2003; 52(7): 552-9.

[PMID: 12841972] 